\title{
Rambling (?) about the image of scientists in meme culture
}

\author{
Tam-Tri Le \\ Centre for Interdisciplinary Social Research \\ Phenikaa University, Hanoi, Vietnam \\ Written in Ho Chi Minh City on 25 September 2021
}

Caution: this paper contains sarcastic informal-culture language and may induce cringe!

There are quite a variety of interesting stereotypes about scientists in the general entertainment media; to name a few: stone-cold computer-like geniuses (those "guys in white lab coats"), accidental villains with incredible passion and questionable moral standards (the typical "mad scientists"), or plain mysterious embodiments of futuristic wisdom (the good old "Professors").

In the relatively less exciting reality, we also have several unfortunate perceptions on certain stereotypes of scientists, such as: the unmotivated university professors (probably dubbed "Dr. Sleeping-Pill"), the hyper-active scientific social-media celebrities (the Internet's favorite "science guys"), and those who work on forbidden experiments in secret underground bunkers (?) perhaps only known by some wacky conspiracy theorists.

I have played video games featuring overly macho combat-maniac scientists as protagonists in battles against puny aliens or meaty mutants; and some gorgeous lab-coat ladies who hack the government's secret system to kill time. I wish they could have added some details like writing lengthy reports hopelessly asking for funding or waiting several eternities for papers to be published, just to make it a little bit more realistic, you know.

From many corners of the Internet, science memes are normally over-the-top, with various comedic implications of ultra-ignorance or useless ingeniousness (or just some simple random toddler-level facts - modern humor is rather special). Better yet, popular memes often come with multiple verbose versions, for those mighty intellectuals who love unnecessary jargon. Nevertheless, the high-quality ("based" and "dank") memes can be a very effective communicative channel for conveying the "cool side" of being a scientist to the digital public. But familiarity and proper knowledge of meme culture are required to avoid counter-effective practices - creating memes that are considered "stale", "normie", "cringe", or worst of all, "sus".

Jokes aside, do I personally feel that doing science is exciting? Yes, absolutely. But is it "cool"? Well, I am currently a very young scientist, but within my circle, I know about the author of a scientific-historical book who literally became the country's leader (Pham \& Vuong, 2009), and I fortunately had the chance to work on a theoretical book about the psychology-based principles for global counter-terrorism (Vuong et al., 2021). So personally, yes, on meme culture's standard, I think it is pretty "pog"! 


\section{References}

Chính, P. M., \& Hoàng, V. Q. (2009). Kinh tế Việt Nam: Thăng trầm và Đột phá. Nxb Chính trị Quốc gia, Hà Nội.

Vuong, Q.-H., Nguyen, M.-H., \& Le, T.-T. (2021). A Mindsponge-Based Investigation into the Psycho-Religious Mechanism Behind Suicide Attacks. Sciendo.

https://doi.org/10.2478/9788366675599 